\title{
Uréia para Vacas em Lactação. 2. Estimativas do Volume Urinário, da Produção Microbiana e da Excreção de Uréia ${ }^{1}$
}

\author{
Rosângela Maria Nunes da Silva ${ }^{2}$, Rilene Ferreira Diniz Valadares ${ }^{3}$, \\ Sebastião de Campos Valadares Filho ${ }^{3}$, Paulo Roberto Cecon ${ }^{3}$, Luciana Navajas Rennó ${ }^{4}$, \\ Juliana Munique da Silva ${ }^{5}$
}

RESUMO - Esta pesquisa foi desenvolvida, utilizando 15 vacas lactantes (Holandês x Gir) alimentadas à vontade com rações isoprotéicas constituídas de $60 \%$ de silagem e $40 \%$ de concentrado na matéria seca (MS) e $0 ; 0,7 ; 1,4 ;$ e $2,1 \%$ de uréia, correspondentes aos teores de 2,$08 ; 4,01 ; 5,76$; e 8,07\% de proteína bruta na forma de compostos nitrogenados não-protéicos (NNP), com os objetivos de desenvolver metodologia não-invasiva, para estimar a produção de proteína microbiana, utilizando-se a excreção total de derivados de purinas (DP); avaliar as concentrações de creatinina, uréia e N-uréia no plasma e no leite; e comparar as excreções de DP e uréia obtidas a partir de coletas de urina total e spot. Os animais tinham peso vivo médio inicial de $511,8 \mathrm{~kg}$ e foram distribuídos ao acaso entre tratamentos. O período experimental teve duração de 90 dias para cada vaca, iniciando-se imediatamente após o parto. Os resultados obtidos foram avaliados estatisticamente por análises de variância e de regressão. As amostras de urina foram obtidas a partir de coletas com 24 horas de duração ou a partir de amostra de urina obtida aproximadamente 4 horas após a alimentação (urina spot), enquanto as de sangue foram obtidas 4 horas após o fornecimento do alimento. As concentrações de uréia e N-uréia no plasma e leite, assim como a excreção de creatinina, que apresentou valor médio de $23,60 \mathrm{mg} / \mathrm{kg}$ PV, não foram afetadas pela adição de quantidades crescentes de NNP à ração. As excreções urinárias de uréia, alantoína, ácido úrico e DP, as purinas absorvidas e a produção de $\mathrm{N}$ microbiano não foram influenciadas pela dieta. As excreções diárias estimadas de uréia, alantoína e ácido úrico seguiram o mesmo padrão obtido pela coleta de 24 horas de duração. Amostra spot de urina foi capaz de estimar satisfatoriamente a excreção de DP e, subseqüentemente, a produção de N microbiano.

Palavras-chave: creatinina, derivados de purinas, leite, plasma, urina

\section{Urea for Dairy Cows. 2. Estimates of Urinary Volume, Microbial Production and Urea Excretion}

\begin{abstract}
This research was carried out, using 15 dairy cows (Holstein x Gyr) full fed isoproteic diets with $60 \%$ silage and $40 \%$ concentrate in the dry matter (DM) basis and $0,0.7,1.4$, and $2.1 \%$ urea correspondent to $2.08,4.01,5.76$, and $8.07 \%$ of crude protein levels in the form of non protein nitrogen compounds (NNP), with the objectives to a non invasive methodology, to estimate the microbial protein production, using the total excretion of purine derivatives (PD); to evaluate the concentrations of creatinine, urea and N-urea in the plasma and in the milk; and to compare the PD and urea excretions obtained from total urine and spot collections. The animals averaging initial live weight of $511.8 \mathrm{~kg}$ were randomized allotted to the treatments. The experimental period last 90 days for each cow, starting immediately after calving. The results were interpreted by variance and regression analyses. The urine samples were obtained from 24-h collections or from urine sample obtained, approximately, four hours post feeding (spot urine), while the blood samples were obtained four hours post feeding offer. The urea and N-urea concentrations in the plasma and in the milk, as well as the creatinine excretion, that showed average value of $23.60 \mathrm{mg} / \mathrm{kg} \mathrm{LW}$, were not affected by the addition of increasing NNP levels to the diet. The urinary excretions of urea, allantoin, uric acid and PD, the absorbed purines and the microbial $N$ production were not influenced by dietary NNP levels. The daily estimated excretions of urea, allantoin and uric acid followed the same pattern obtained by the 24-h collection. Urine spot sample was satisfactory to estimate the PP excretion and, subsequently, the microbial $\mathrm{N}$ production.
\end{abstract}

Key Words: creatinine, purine derivatives, milk, plasma, urine

\footnotetext{
1 Parte da tese de Mestrado apresentada à Universidade Federal de Viçosa. Projeto financiado pela FAPEMIG.

2 Professora da UFPB.

3 Professor da UFV. E.mail: rilene@mail.ufv.br; scvfilho@mail.ufv.br

${ }^{4}$ Estudante de Doutorado.

${ }^{5}$ Bolsista de Iniciação Científica.
} 


\section{Introdução}

As proteínas são fontes de aminoácidos (AA), componentes essenciais de todas as dietas (CUNNINGHAN, 1993). Nos ruminantes, as exigências de proteínas são supridas pelos AA absorvidos no intestino delgado, os quais são provenientes da proteína microbiana (sintetizada no rúmen) e da proteína dietética não degradada no rúmen digestível (PNDR), (MERCHEN e BOURQUIN, 1994).

NOLAN (1993) concluiu que a taxa de degradação de carboidratos, as fontes de compostos nitrogenados $(\mathrm{N})$ no rúmen (amônia, peptídeos, aminoácidos), o enxofre presente na dieta e a freqüência de alimentação são fatores que podem afetar o crescimento e a síntese de proteína microbiana.

Segundo CLARK et al. (1992), energia e N são os fatores nutricionais que mais afetam o crescimento microbiano. Segundo os mesmos autores, taxas mais rápidas de crescimento acopladas a passagens mais rápidas de microrganismos para o intestino delgado (ID) podem reduzir a reciclagem de energia e $\mathrm{N}$ no rúmen por causa de um decréscimo na lise das células, decrescendo, assim, as exigências para mantença, fornecendo mais nutrientes disponíveis para o crescimento microbiano, o que melhora a eficiência de síntese microbiana no rúmen. Desse modo, é de fundamental importância o conhecimento da produção de proteína microbiana.

De acordo com NOCEK e RUSSEL (1988), CECAVA et al. (1990) e HOOVER e STOKES (1991), a síntese de proteína microbiana está relacionada com a quantidade consumida de matéria seca ou matéria orgânica digerida no rúmen e com a eficiência com que os microrganismos utilizam a energia, um dos fatores limitantes para o crescimento microbiano. SNIFFEN e ROBINSON (1987) relataram que, quando os açúcares e o amido encontramse em elevadas proporções na ração, há elevação nas taxas de crescimento de microrganismos fermentadores de carboidratos não estruturais ( $\mathrm{CNE}$ ), e, se o $\mathrm{pH}$ ruminal for mantido dentro de limites fisiológicos, a produção microbiana será maximizada. Porém, se houver acúmulo de ácido láctico no rúmen e conseqüente diminuição nos valores de $\mathrm{pH}$ desse compartimento, a microbiota ruminal será alterada provocando redução na eficiência microbiana e na ingestão de matéria seca (MS) pelo animal.

Diversos métodos empregados na estimativa da quantidade de compostos nitrogenados microbianos baseiam-se em marcadores microbianos. Entre eles citam-se a utilização da dieta purificada, ácido 2,6 diaminopimélico (DAPA), ácidos nucléicos (RNA) e os isótopos $\mathrm{N}^{15}, \mathrm{~S}^{35}$ e $\mathrm{P}^{32}$ (BRODERICK e MERCHEN, 1992). Entretanto, esses métodos são trabalhosos e requerem a utilização de animais fistulados no abomaso ou ID, o que não é recomendável para a saúde animal, e a estimativa de fluxo de digesta, processo laborioso e impreciso (VAGNONI et al., 1997). Segundo TIMMERMANS JR. et al. (2000), devido a estas limitações, tem havido interesse crescente no desenvolvimento de técnicas nãoinvasivas para estimar a produção de $\mathrm{N}$ microbiano.

Estudos realizados há mais de trinta anos demonstraram que a quantidade de $\mathrm{N}$ excretada na urina por ovinos, como alantoína e ácido úrico, foi correlacionada com a concentração de ácidos nucléicos no rúmen (Topps e Elliott, 1965, citados por STANGASSINGER et al., 1995; e JOHNSON et al., 1998). Segundo FUJIHARA et al. (1987), o uso da excreção urinária de derivados de purinas (DP) como marcador metabólico da síntese microbiana foi proposta inicialmente por Blaxter e Martin, em 1962 e por Topps e Elliot, em 1965. Entretanto maiores progressos no estabelecimento de um método relacionando a excreção de DP e a produção microbiana só mais recentemente foram feitos (MAYES et al., 1995).

A técnica de determinação da excreção urinária de DP admite que os ácidos nucléicos no duodeno são de origem predominantemente microbiana e, após digestão intestinal e absorção, tais derivados são proporcionalmente recuperados na urina, principalmente na forma de alantoína, mas também como hipoxantina, xantina e ácido úrico (PEREZ et al., 1996).

A enzima-chave na degradação de purinas é a xantina oxidase, que converte hipoxantina e xantina em ácido úrico. Este, então, consiste no produto final do catabolismo das purinas, porém, na maioria dos mamíferos, o ácido úrico é degradado ao produto de excreção alantoína pela ação da uricase (LENINGHER et al., 1995). Segundo CHEN e GOMES (1992), na urina de bovinos apenas alantoína e ácido úrico estão presentes, devido à grande atividade de xantina oxidase no sangue e tecidos, que converte xantina e hipoxantina a ácido úrico antes da excreção.

FUNABA et al. (1997), VAGNONI et al. (1997) e MOSCARDINI et al. (1998) utilizaram as excreções de alantoína e ácido úrico para representar o total de excreção urinária de DP. VAGNONI et al. (1997) e JOHNSON et al. (1998) concluíram que a excreção 
urinária de DP apresentou correlação positiva com a estimativa do fluxo de $\mathrm{N}$ microbiano no duodeno.

Os dois parâmetros que necessitam ser definidos para estimativa do fluxo de proteína microbiana no duodeno, a partir da excreção de DP na urina, são a recuperação das purinas absorvidas e a relação Npurina: $\mathrm{N}$ total dos microrganismos ruminais, que é bastante variável (MAYES et al., 1995; VAGNONI e BRODERICK, 1997). Segundo CHEN et al. (1996), a excreção urinária de DP pelos ruminantes pode ser usada para estimar o fluxo intestinal de proteína microbiana, uma vez que a relação quantitativa entre a excreção de DP e absorção de purinas tenha sido determinada.

O método para estimar a produção microbiana baseado na excreção de DP requer coleta total de urina, entretanto supera as desvantagens dos métodos citados anteriormente, uma vez que não requer qualquer procedimento cirúrgico e tem o potencial de vir a ser simplificado para ser usado em condições de campo (CHEN e GOMES, 1992).

A amônia ruminal, resultante do processo de proteólise bacteriana, que não é incorporada aos ácidos nucléicos, aminoácidos ou, eventualmente à proteína microbiana, é absorvida através da parede do rúmen (CHURCH, 1988), rota principal para a amônia que não foi assimilada pelos microrganismos. Em seguida, é transportada através do sistema vascular porta-hepático para o fígado, onde é convertida em uréia (VISEK, 1979; DEPETERS e FERGUSSON, 1992), constituindo a principal forma pela qual o Né eliminado do organismo dos mamíferos. Nos ruminantes, parte da uréia sangüínea é reciclada para o rúmen através da saliva ou por difusão através do epitélio ruminal, e outra parte excretada na urina (LOBLEY et al., 1995). A potencialidade de reciclagem da uréia para o rúmen eleva-se quando esse composto está presente em alta concentração sangüínea, havendo grande atividade de urease ruminal, diminuição da concentração ruminal de amônia e redução do $\mathrm{pH}$ do rúmen (SIDDONS et al., 1985).

Quando a velocidade de síntese da amônia pelos microrganismos supera a sua utilização, há uma elevação das concentrações de $\mathrm{NH}_{3}$ no rúmen, aumentando a excreção de compostos nitrogenados e o custo energético da produção de uréia (RUSSEL et al., 1992), resultando em perda de nitrogênio (MORRISON e MACKIE, 1996).

Durante períodos de alta disponibilidade ruminal de N, observam-se elevadas concentrações sangüíneas de uréia. Vários autores, dentre os quais, THORNTON e WILSON (1972), ROSELER et al. (1993), THOMSON et al.(1995), VALADARES et al. (1997a) e MOSCARDINI et al. (1998), demonstraram que a concentração plasmática de uréia é positivamente relacionada com a ingestão de $\mathrm{N}$.

Tentativas têm sido feitas para utilizar a concentração plasmática de uréia como índice para estimativa do pool de uréia (HARMEYER e MARTENS, 1980) e da degradabilidade da proteína (Bertoni et al., 1989, citados por ROSELER et al., 1993) ou como indicador da condição nutricional (GUSTAFSSON e PALMQUIST, 1993). Isso se baseia no fato de que a uréia é sintetizada no fígado em quantidades proporcionais à concentração de amônia produzida no rúmen, e sua concentração sangüínea está diretamente relacionada com o aporte protéico da ração e com a relação energia:proteína desta (HARMEYER e MARTENS, 1980). Para BRODERICK (1995), a concentração plasmática elevada de uréia está relacionada com a utilização ineficiente de proteína.

Segundo HARMEYER e MARTENS (1980), a quantidade de uréia excretada pelos rins depende dos seguintes fatores: concentração plasmática de uréia, taxa de filtração glomerular (TFG) e reabsorção tubular de uréia. Os mesmos autores afirmaram que a concentração plasmática de uréia é o principal fator regulador da sua excreção renal sob uma variedade de condições dietéticas.

A uréia sangüínea difunde-se através do epitélio alveolar da glândula mamária para o leite, e tem sido relatada elevada correlação positiva entre a concentração de N-uréia no leite (NUL) e a N-uréia no plasma (NUP), sugerindo que NUL e NUP poderiam ser utilizadas como indicadores do metabolismo protéico em vacas (WITTWER et al.,1993; ROSELER et al., 1993; BRODERICK e CLAYTON, 1997; JONKER et al., 1998). Normalmente o NUL contribui com $50 \%$ dos compostos nitrogenados não protéicos do leite (ROSELER et al., 1993).

Poucos experimentos utilizando fêmeas com cateteres tem sido descritos, tais como SUSMEL et al. (1994), VAGNONI et al. (1997), VALADARES et al. (1997b) e VALADARES et al. (1999). Nesses experimentos o período de coleta variou entre 1 e 5 dias. Na medida em que o uso de cateteres pode representar desconforto, principalmente para animais lactantes e gestantes, é importante o desenvolvimento de metodologias que permitam o menor tempo possível de coleta de urina ou até mesmo que 
tornem desnecessária a coleta total de urina, como as estimativas baseadas na excreção de creatinina utilizando coleta de urina spot.

Tem havido vários registros na literatura demonstrando ser a excreção de creatinina uma função constante do peso vivo (TOPPS e ELLIOTT, 1967; SUSMEL et al., 1994; VAGNONI et al., 1997; VALADARES et al.,1997b), e parece possível a utilização de creatinina como marcador para estimativa do volume urinário. Isto poderia permitir a estimativa da excreção de DP e de outros compostos nitrogenados, sem a coleta total de urina (CHEN et al., 1995).

VALADARES et al. (1999) estimaram as excreções diárias de DP a partir de amostras spot de urina e diferenças entre o volume medido e o estimado só foram significativas para $35 \%$ de concentrado na dieta, não havendo diferenças para 20, 50 e $65 \%$ de concentrados.

Outras alternativas para estimativa da produção microbiana, em condições de campo, incluiriam as concentrações de alantoína no plasma ou leite. GIESECKE et al. (1994) descreveram altas correlações entre concentrações de alantoína no plasma e no leite e a excreção urinária total de alantoína. Entretanto, GONDA e LINDBERG (1997) concluíram que a excreção de alantoína no leite não seria um indicador confiável do fluxo de proteína microbiana para o duodeno em vacas lactantes.

A adequação da ingestão de $\mathrm{N}$ e energia em vacas leiteiras tem demonstrado a sua importância, devido a maiores demandas para a produção de proteína do leite em relação a outros constituintes. Além disso, uma ingestão excessiva de $\mathrm{N}$ pode comprometer o desempenho reprodutivo, bem como aumentar as exigências energéticas da dieta (13,3 kcal da energia digestível/g do excesso de $\mathrm{N})$. Outros fatores consistem em um impacto negativo sobre o meio ambiente (BRODERICK e CLAYTON, 1997) e, nas condições brasileiras, suplementos protéicos na alimentação elevam significativamente os custos de produção, podendo-se amenizar tal problema fazendo uso de NNP (uréia) em substituição ao farelo de soja.

Objetivou-se com o presente experimento: a) determinar a metodologia não invasiva, para estimar a produção de proteína microbiana, utilizando-se a excreção total de derivados de purinas (DP); b) avaliar as concentrações de creatinina, uréia e N-uréia no plasma e no leite e comparar as excreções de DP e uréia obtidas a partir de coletas de urina total e spot

\section{Material e Métodos}

O local, as instalações, os constituintes e a composição das rações, o manejo e o delineamento experimental foram descritos por SILVA et al. (2000).

Os resultados foram avaliados por meio de análises de variância e regressão, utilizando-se o programa SAEG - Sistema de Análises Estatísticas e Genéticas (UFV, 1998). Os modelos foram escolhidos com base na significância dos coeficientes de regressão utilizando-se o teste de $\mathrm{F}$ e no coeficiente de determinação $R^{2}$, que foi calculado baseado na divisão da Soma de Quadrado (SQ) da regressão pela SQ de Tratamento $\left(\mathrm{R}^{2}=\mathrm{SQR}\right.$ egressão/SQTratamento). Para as comparações entre as médias obtidas e estimadas para as variáveis volume urinário, excreções urinárias de uréia, alantoína, ácido úrico, purinas totais, purinas absorvidas e produção de $\mathrm{N}$ microbiano, utilizou-se o teste $\mathrm{F}$, a $5 \%$ de probabilidade.

A partir das $13 \mathrm{~h}$ do $38^{\circ}$ dia do período experimental, foram realizadas coletas de urina de cada animal durante 24 horas, utilizando-se sondas de Folley n ${ }^{\circ} 26$, duas vias, com balão de $30 \mathrm{~mL}$ adaptadas com auxílio de espéculo vaginal e guia de sonda, via uretra até a bexiga urinária (VALADARES et al., 1997a). Na extremidade livre da sonda foi adaptado tubo de polietileno, pelo qual a urina foi conduzida até baldes de plástico com tampa, contendo $500 \mathrm{~mL}$ de $\mathrm{H}_{2} \mathrm{SO}_{4}$ a $20 \%$. Ao término de $24 \mathrm{~h}$ de coleta, a urina foi pesada, homogeneizada, e alíquotas de $10 \mathrm{~mL}$ foram diluídas com $40 \mathrm{~mL}$ de $\mathrm{H}_{2} \mathrm{SO}_{4}$ a $0,036 \mathrm{~N}$. Estas amostras tiveram o $\mathrm{pH}$ ajustado para valores inferiores a 3 para evitar destruição bacteriana das bases purinas urinárias e a precipitação do ácido úrico. Posteriormente, foram armazenadas $\mathrm{a}-20^{\circ} \mathrm{C}$ até serem submetidas à determinação de creatinina, uréia, alantoína e ácido úrico.

As amostras spot de urina foram obtidas por micção espontânea no $30^{\circ}$ dia do experimento, aproximadamente 4 horas após o fornecimento da alimentação. O processamento dessas amostras ocorreu de modo similar àquelas obtidas em coletas com 24 horas de duração. Ao final do experimento, essas foram descongeladas e analisadas para determinação de creatinina, uréia, alantoína e ácido úrico.

Simultaneamente à coleta spot de urina, também foram obtidas amostras de sangue de cada animal, por punção da veia coccígea média. O sangue contendo heparina como anticoagulante foi imediatamente centrifugado a $5000 \mathrm{rpm}$ durante 15 minutos e o plasma foi armazenado a $-20^{\circ} \mathrm{C}$. Posteriormente, o 
plasma foi descongelado à temperatura ambiente e analisado para determinação de uréia e creatinina.

Ao $30^{\circ}$ dia da fase experimental, amostras de leite da $1^{\mathrm{a}}$ e $2^{\mathrm{a}}$ ordenhas de cada animal foram coletadas, sendo posteriormente compostas e desproteinizadas com ácido tricloroácético (TCA) a $25 \%$, numa proporção 10 leite:5 TCA. As amostras de leite desproteinizadas foram acondicionadas em vidros com tampa e armazenadas a $-20^{\circ} \mathrm{C}$ até o momento de serem submetidas à determinação de uréia e alantoína.

As análises de uréia e creatinina na urina, no sangue e no leite, foram feitas segundo os métodos diacetil modificado e com uso de picrato e acidificante (Kit Analisa), respectivamente. As análises de alantoína e ácido úrico, na urina e no leite desproteinizado, foram feitas pelo método colorimétrico, conforme técnica de FUJIHARA et al. (1987), descrita por CHEN e GOMES (1992).

O clearance ou depuração plasmática da creatinina foi calculado a partir do produto do volume de urina de 24 horas pela concentração de creatinina urinária dividido pela concentração de creatinina no plasma, sendo expresso em $\mathrm{mL} / \mathrm{min} / \mathrm{kg} \mathrm{PV}$.

A partir da excreção média diária de creatinina, obtida no experimento em $\mathrm{mg} / \mathrm{kg} \mathrm{PV} /$ dia, e da concentração de creatinina $(\mathrm{mg} / \mathrm{L})$ na amostra spot de urina, foi estimado o volume diário de urina. Esse volume foi utilizado para calcular as excreções estimadas diárias de uréia, alantoína e ácido úrico de cada animal, que foram comparadas com as obtidas a partir de coletas de urina de 24 horas de duração.

As excreções diárias estimada e obtida de $\mathrm{N}$-uréia foram calculadas pelo produto das concentrações urinárias de uréia pelo volume urinário de 24 horas ou pelo volume estimado, multiplicado por 0,466 , correspondente ao teor de $\mathrm{N}$ na uréia.

A excreção total de DP foi o resultado da soma das excreções urinárias de alantoína e ácido úrico mais a excreção de alantoína no leite.

As purinas microbianas absorvidas (X, mmol/dia) foram calculadas a partir da excreção de derivados de purinas (Y, mmol/dia), utilizando a seguinte equação (Verbic et al., 1990, citados por CHEN e GOMES, 1992): $\mathrm{Y}=0,85 \mathrm{X}+0,385 \mathrm{PV}^{0,75}$, em que 0,85 é a recuperação de purinas absorvidas como derivados de purina na urina e $0,385 \mathrm{PV}^{0,75}$ representa a contribuição endógena para a excreção de purinas.

O fluxo intestinal de compostos nitrogenados (N) microbianos (Y, gN/dia) foi calculado em função das purinas absorvidas (X, mmol/dia), utilizando-se a equação: $\mathrm{Y}=(70 \mathrm{X}) /(0,83 \times 0,134 \times 1000)$, em que 70 representa o conteúdo de $\mathrm{N}$ nas purinas $(\mathrm{mgN} / \mathrm{mmol})$; 0,83 , a digestibilidade das purinas microbianas; e 0,134, a relação $\mathrm{N}$-purina: $\mathrm{N}$ total nas bactérias (VALADARES et al., 1999).

\section{Resultados e Discussão}

Observam-se, na Tabela 1, as médias de volume urinário, as excreções urinárias de uréia, alantoína, ácido úrico, purinas totais, purinas absorvidas e produção de $\mathrm{N}$ microbiano (Nmic) obtidas pela coleta total e estimadas a partir de amostras spot.

As médias dos volumes urinários obtido e estimado foram de 10,87 e 11,11 L/dia, respectivamente, não havendo diferença $(\mathrm{P}>0,05)$ entre as determinações. $\mathrm{O}$ mesmo se aplica às médias obtidas e estimadas para excreção de uréia, alantoína, ácido úrico, para as purinas totais, purinas absorvidas e produção de $\mathrm{N}$ microbiana. Portanto, amostra spot de urina pareceu estimar satisfatoriamente o volume urinário e as excreções de uréia e DP e, subseqüentemente, a produção de $\mathrm{N}$ microbiano.

Constam da Tabela 2 os volumes urinários obtido e estimado, as excreções estimadas e obtidas de creatinina e uréia, de derivados de purinas (DP), representados por alantoína, ácido úrico, derivados de purinas totais e purinas absorvidas, e as produções estimada e obtida de compostos nitrogenados

Tabela 1 - Médias obtidas e estimadas do volume urinário (V), excreções urinárias de uréia (U), alantoína (ALA), ácido úrico $(A U)$, purinas totais $(P T)$, purinas absorvidas (PAB) e produção de $\mathrm{N}$ microbiano (Nmic)

Table 1 - Obtained and estimated means of urinary volume (V), urinary excretions of urea $(U)$, allantoin $(A L A)$, uric acid (UA), total purines (TP), absorbed purines (AP) and microbial $N$ production (Nmic)

\begin{tabular}{lccc}
\hline Itens & \multicolumn{2}{c}{$\begin{array}{c}\text { Médias } \\
\text { Means }\end{array}$} & $\mathrm{P}$ \\
\cline { 2 - 3 } & $\begin{array}{c}\text { Obtida } \\
\text { Obtained }\end{array}$ & $\begin{array}{c}\text { Estimada } \\
\text { Estimated }\end{array}$ \\
\hline $\mathrm{V}(\mathrm{L})$ & 10,87 & 11,11 & $\mathrm{~ns}$ \\
$\mathrm{U}(\mathrm{mg} / \mathrm{kg} \mathrm{PV})$ & 361,38 & 388,48 & $\mathrm{~ns}$ \\
$\mathrm{ALA}(\mathrm{mmol} / \mathrm{dia})$ & 221,74 & 225,73 & $\mathrm{~ns}$ \\
$\mathrm{AU}(\mathrm{mmol} / \mathrm{dia})$ & 29,07 & 24,22 & $\mathrm{~ns}$ \\
$\mathrm{PT}(\mathrm{mmol} / \mathrm{dia})$ & 289,29 & 303,17 & $\mathrm{~ns}$ \\
$\mathrm{PAB}(\mathrm{mmol} /$ dia $)$ & 291,15 & 307,85 & $\mathrm{~ns}$ \\
Nmic $(\mathrm{g} \mathrm{Nmic} /$ dia $)$ & 183,15 & 193,64 & $\mathrm{~ns}$ \\
\hline
\end{tabular}

ns não-significativo a $5 \%$ de probabilidade pelo teste $\mathrm{F}$.

ns not significant at $5 \%$ of probability by $F$ test. 
microbianos (Nmic), correspondentes aos teores de NNP na ração, os respectivos coeficientes de variação $(\mathrm{CV})$ e os níveis de significância (P) para os efeitos linear (L) e quadrático (Q). Nenhuma das variáveis constando na Tabela 2 foram afetadas significativamente $(\mathrm{P}>0,05)$ pelo teor de NNP na matéria seca (MS) da dieta.

Os volumes urinários obtidos e estimados não foram influenciados $(\mathrm{P}>0,05)$ pelos teores de NNP dietéticos. VALADARES et al. (1999) também não obtiveram diferenças entre os volumes urinários estimado e obtido para dietas com teores de 20; 50 e $65 \%$ de concentrado.

A excreção média de creatinina na urina foi de $23,60 \mathrm{mg} / \mathrm{kg} \mathrm{PV}$, e não foram observadas diferenças $(\mathrm{P}>0,05)$ em função do NNP dietético. VALADARES et al. (1997a), ao utilizarem diferentes níveis de proteína bruta (PB) na ração, obtiveram médias de 21,47 e 25,16 $\mathrm{mg} / \mathrm{kg}$ PV em experimentos com vacas gestantes e lactantes, respectivamente. Há vários relatos demonstrando ser a excreção de creatinina uma função constante do peso vivo (TOPPS e ELLIOTT, 1967; SUSMEL et al., 1994; VAGNONI et al., 1997; VALADARES et al., 1997a; RENNÓ, 1999), o que possibilita sua utilização para estimativa do volume urinário.
Mesmo não apresentando diferença $(\mathrm{P}>0,05)$, os dois maiores níveis de NNP da dieta, 5,76 e 8,07\%, registraram as maiores excreções de uréia na urina, que foram, respectivamente, 434,51 e 442,55 mg/ $\mathrm{kg} \mathrm{PV}$, quando obtidas com coleta total e 494,73 e 465,34 mg/kg $\mathrm{PV}$, utilizando-se urina spot. Vários dados da literatura demonstraram que o aumento da ingestão de $\mathrm{N}$ na forma de uréia aumenta significativamente a quantidade de $\mathrm{N}$ eliminado na urina (SUSMEL et al., 1995a), fator este que não foi detectado no experimento, atribuindo-se, então, ao tipo de delineamento experimental utilizado.

As excreções urinárias obtida e estimada de alantoína variaram de 169,39 a 291,23 mmol/dia e de 179,75 a $284,56 \mathrm{mmol} / \mathrm{dia}$, respectivamente. Ao pesquisarem os efeitos da dieta sobre a concentração e excreção de alantoína no leite e a relação entre alantoína no leite e na urina em vacas leiteiras, GONDA e LINDBERG (1997) obtiveram excreções urinárias de alantoína variando de 211 a $571 \mathrm{mmol} /$ dia, enquanto JOHNSON et al. (1998) relataram média de 191,5 mmol/dia. Estas variações de valores encontrados na literatura indicaram que o nível de alantoína e ácido úrico em vacas leiteiras não é constante em todos os estádios fisiológicos e tratamentos dietéticos (JOHNSON et al., 1998).

Tabela 2 - Médias diárias obtidas $(\mathrm{O})$ e estimadas $(\mathrm{E})$ dos volumes urinários $(\mathrm{V})$, das excreções urinárias de creatinina (CR), uréia $(U)$, alantoína (ALA), ácido úrico (AU), excreção de alantoína no leite (ALAL), purinas totais (PT), purinas absorvidas (PAB) e $\mathrm{N}$ microbiano (Nmic), em função dos teores de compostos nitrogenados não-protéicos (NNP) das rações, coeficiente de variação $(C V)$ e nível de probabilidade $(P)$ dos efeitos linear $(L)$ e quadrático $(Q)$

Table 2 - Obtained $(O)$ and estimated $(E)$ daily means of urinary volume (V), urinary excretions of creatinine (CR), urea (U), allantoin (ALA), uric acid (UA), allantoin excretion in the milk (ALAL), total purines (TP), absorbed purines (AP) and microbial N production (Nmic), in function of the dietary non protein nitrogen compounds (NPN) contents, coefficient of variation (CV) and level of probability of linear $(L)$ and quadratic ( $Q$ ) effects

\begin{tabular}{|c|c|c|c|c|c|c|c|}
\hline \multirow[t]{2}{*}{$\begin{array}{l}\text { Variáveis } \\
\text { Variables }\end{array}$} & \multicolumn{4}{|c|}{$\begin{array}{l}\text { Teores de NNP }(\%) \\
\text { NPN contents }\end{array}$} & \multirow[t]{2}{*}{ CV $(\%)$} & \multicolumn{2}{|c|}{$\mathrm{P}$} \\
\hline & 2,08 & 4,01 & 5,76 & 8,07 & & $\mathrm{~L}$ & Q \\
\hline $\mathrm{VO}(\mathrm{L})$ & 8,20 & 10,65 & 12,33 & 12,67 & 50,94 & n.s. & n.s. \\
\hline VE(L) & 7,62 & 12,38 & 12,39 & 12,36 & 53,63 & n.s. & n.s. \\
\hline $\mathrm{CR}(\mathrm{mg} / \mathrm{kg} \mathrm{PV})$ & 23,34 & 23,78 & 25,09 & 22,23 & 12,26 & n.s. & n.s. \\
\hline $\mathrm{UO}(\mathrm{mg} / \mathrm{kg} \mathrm{PV})$ & 330,18 & 256,56 & 434,51 & 442,55 & 32,70 & n.s. & n.s. \\
\hline $\mathrm{UE}(\mathrm{mg} / \mathrm{kg} \mathrm{PV})$ & 351,25 & 269,16 & 494,73 & 465,34 & 35,20 & n.s. & n.s. \\
\hline $\mathrm{ALAO}(\mathrm{mmol})$ & 209,64 & 203,62 & 169,39 & 291,23 & 55,75 & n.s. & n.s. \\
\hline $\operatorname{ALAE}(\mathrm{mmol})$ & 194,16 & 232,97 & 179,75 & 284,56 & 60,21 & n.s. & n.s. \\
\hline $\mathrm{AUO}(\mathrm{mmol})$ & 23,78 & 30,77 & 25,19 & 35,59 & 26,58 & n.s. & n.s. \\
\hline AUE (mmol) & 18,06 & 17,11 & 17,67 & 42,41 & 79,75 & n.s. & n.s. \\
\hline ALAL (mmol) & 11,54 & 13,72 & 10,91 & 11,40 & 16,81 & n.s. & n.s. \\
\hline PTO (mmol) & 291,58 & 305,58 & 205,49 & 338,21 & 38,48 & n.s. & n.s. \\
\hline PTE (mmol) & 262,64 & 435,86 & 208,33 & 338,37 & 36,00 & n.s. & n.s. \\
\hline PABO (mmol) & 293,49 & 306,68 & 195,65 & 349,38 & 45,09 & n.s. & n.s. \\
\hline PABE (mmol) & 259,45 & 460,36 & 198,98 & 349,56 & 41,75 & n.s. & n.s. \\
\hline $\mathrm{NmicO}(\mathrm{gNmic})$ & 184,61 & 192,90 & 123,06 & 219,76 & 45,09 & n.s. & n.s. \\
\hline NmicE (g Nmic) & 163,19 & 289,57 & 125,16 & 219,87 & 41,75 & n.s. & n.s. \\
\hline
\end{tabular}

ns não-significativo a $5 \%$ de probabilidade pelo teste $\mathrm{F}$.

ns not significant at $5 \%$ of probability by $F$ test.

Rev. bras. zootec., 30(6):1948-1957, 2001 
As excreções urinárias de ácido úrico obtida e estimada, de $28,83 \mathrm{mmol} /$ dia e de $23,81 \mathrm{mmol} / \mathrm{dia}$, respectivamente, foram inferiores àquelas observadas por VALADARES et al. (1999), que corresponderam, respectivamente, a 43,4 e 39,15 mmol/dia. GIESECKE et al. (1994) obtiveram média de $35,2 \mathrm{mmol} / \mathrm{dia}$ na coleta total de urina e JOHNSON et al. (1998), 58,8 mmol/dia. De acordo com esses autores, a excreção de ácido úrico pode ser usada para estimar a produção de $\mathrm{N}$ microbiano em vacas leiteiras durante todos os estádios da lactação, exceto durante o início da mesma, pois, nesta fase, as vacas tendem a excretar mais ácido úrico e menos alantoína, ocorrendo o oposto ao término da lactação. As razões para estas inclinações, segundo os mesmos autores, poderiam ser as diferenças na atividade da uricase no fígado e tecido extra-hepático, alteração na rota de excreção da alantoína e ácido úrico via urina, leite, saliva e outros meios de excreções e alterações na quantidade e na proporção de perdas endógenas de purinas, via urina, devido aos diferentes estádios fisiológicos.

A excreção de ácido úrico apresentou média de $10,83 \%$ do total de DP excretado na urina, o que está de acordo com GIESECKE et al. (1994), que obtiveram 10,6\%. GONDA e LINDBERG (1997) e JOHNSON et al.(1998) obtiverammédias de 3,9e23,5\%, respectivamente.

A secreção de alantoína no leite, que foi em média $11,89 \mathrm{mmol} / \mathrm{dia}$, não foi influenciada $(\mathrm{P}>0,05)$ pelos níveis de NNP da dieta. De acordo com GIESECKE et al. (1994) e GONDA e LINDBERG (1997), a produção de leite parece ser o fator mais importante na determinação da concentração e quantidade da alantoína excretada no leite. Segundo os mesmos autores, alterações no volume de leite poderiam limitar o uso da concentração de alantoína, devido aos efeitos de diluição e produção de alantoína no leite. SUSMEL et al. (1995b) observaram que a secreção de alantoína no leite foi a mais alta, porém não-significativa $(\mathrm{P}>0,05)$, para vacas recebendo uréia na ração. Através de dados obtidos de dez experimentos em vacas leiteiras fistuladas no duodeno, TIMMERMANS JR. et al. (2000) relataram que a secreção de alantoína no leite variou de 5,01 a 11,61 mmol/dia, com média de $8,43 \mathrm{mmol} / \mathrm{dia}$. Segundo os mesmos autores, outros fatores que poderiam influenciar a secreção de alantoína no leite incluem a ingestão de MS, ingestão de energia e fluxo de $\mathrm{N}$ microbiano no duodeno.

No presente experimento obteve-se uma secreção de alantoína no leite em relação a excreção total de DP de 3,37 a 4,49\%; aproximando-se do valor encontrado por VALADARES et al. (1999), que variou de 4,2 a 5,7\%. A quantidade diária de alantoína e ácido úrico secretado no leite, segundo CHEN e GOMES (1992), foi equivalente a $5 \%$ do total excretado na urina. Em contraste com estes resultados, GIESECKE et al. (1994) relataram que a proporção de alantoína no leite foi somente 0,6 a 2,4\%, o que está de acordo com o nível de 0,63 a 1,34\% obtido por GONDA e LINDBERG (1997).

Não foi observado efeito $(\mathrm{P}>0,05)$ dos níveis de NNP sobre a excreção total de DP, obtida e estimada, cujos valores médios foram, respectivamente, 285,27 e $311,3 \mathrm{mmol} / \mathrm{dia}$, acompanhando as purinas absorvidas e a produção de $\mathrm{N}$ microbiano. Efeito semelhante foi relatado por SUSMEL et al. (1995b), ao trabalharem com amostras de urina spot em vacas Simmental e MOSCARDINI et al. (1998), ao avaliarem níveis crescentes de proteína não-degradada no rúmen (PNDR). Dos cinco experimentos com novilhos analisados por RENNÓ (1999), em três as excreções de DP não variaram entre os tratamentos; as excreções médias urinárias de purinas totais foram de 95,36; 104,53 e 105,77 mmol/dia, respectivamente.

A proporção de alantoína urinária em relação à excreção total de DP obtida pela coleta total de urina variou de 71,90 a 86,10\%. CHEN e GOMES (1992) obtiveram valores entre 80 e $85 \%$ e VAGNONI e BRODERICK (1997) observaram uma média de $86,6 \%$. As excreções diárias estimadas de alantoína e DP seguiram o mesmo padrão daquele observado com a coleta total. Segundo VERBIC et al. (1990), a excreção de alantoína na urina reflete a excreção total de DP (85\%); PUCHALA e KULASEK (1992) sugeriram, portanto, não realizar todas as análises dos DP, mas apenas as de alantoína.

A produção de $\mathrm{N}$ microbiano obtida, determinada pela técnica da excreção dos DP e usando a relação de N purina: N total de 0,134 (VALADARES et al., 1999), variou de 123,06 a $219,76 \mathrm{~g} \mathrm{Nmic} / \mathrm{dia}$. VAGNONI e BRODERICK (1997) obtiveram valores variando entre 308 e $362 \mathrm{~g} / \mathrm{d}$, enquanto VALADARES et al. (1999) encontraram valores de 278 a $419 \mathrm{~g} / \mathrm{dia}$, com uma produção microbiana máxima para $35 \%$ de carboidratos não-estruturais da dieta.

SUSMEL et al. (1994) mencionaram que a adição de uréia na dieta aumentou o $\mathrm{N}$ das purinas totais, indicando que a captura de $\mathrm{N}$ dietético pelas bactérias do rúmen foi mais alta nestas dietas e, portanto, a disponibilidade de energia e $\mathrm{N}$ no rúmen parece 
interagir positivamente com o nível de ingestão determinando, acima de tudo, maior eficiência na síntese de proteína microbiana (MOSCARDINI et al., 1998) e, portanto, aumento da produção de leite

De acordo com FUJIHARA et al. (1987), BRODERICK e MERCHEN (1992) e VAGNONI e BRODERICK (1997), a excreção urinária de DP constitui boa alternativa para a estimativa do fluxo de compostos $\mathrm{N}$ microbianos. VALADARES et al. (1999) relataram que amostras spot de urina parecem estimar satisfatoriamente a produção e excreção de DP em vacas leiteiras e, portanto, a produção de $\mathrm{N}$ microbiano, assim como aquela realizada pela coleta total de urina 24 horas. TIMMERMANS JR. et al. (2000) sugeriram existir uma relação positiva entre a secreção de alantoína no leite e o fluxo de $\mathrm{N}$ microbiano no duodeno, e que as produções de alantoína e de leite poderiam ser usadas para predizer o fluxo de $\mathrm{N}$ microbiano; entretanto, mais pesquisas são necessárias para confirmar tais resultados.

$\mathrm{Na}$ Tabela 3 são apresentados o clearance da creatinina, expresso em $\mathrm{mL} / \mathrm{min} / \mathrm{kg} \mathrm{PV}$, as concentrações plasmáticas de creatinina, uréia e N-uréia, $\mathrm{em} \mathrm{mg/dL,} \mathrm{N-uréia} \mathrm{no} \mathrm{leite,} \mathrm{em} \mathrm{g/dia,} \mathrm{e} \mathrm{a} \mathrm{relação} \mathrm{N}$ uréia: $N$ total, em porcentagem (\%), em função dos níveis de NNP da ração, bem como os respectivos coeficientes de variação e os níveis de significância (P) para os efeitos linear $(\mathrm{L})$ e quadrático $(\mathrm{Q})$.

O clearance da creatinina, uma medida da taxa de filtração glomerular, não foi afetado $(\mathrm{P}>0,05)$ pelos teores de NNP da dieta. A média geral do clearance da creatinina de $2,0 \mathrm{~mL} / \mathrm{min} / \mathrm{kg}$ $\mathrm{PV}$ aproximou-se do valor de $1,47 \mathrm{~mL} / \mathrm{min} / \mathrm{kg} \mathrm{PV}$ obtido por VALADARES et al. (1997a).

A concentração plasmática de creatinina apresentou variações de 1,10 a $1,33 \mathrm{mg} / \mathrm{dL}$, não se observando diferenças entre os tratamentos. Comportamento semelhante foi descrito por VALADARES et al. (1999), cujos resultados variaram de 0,97 a $1,10 \mathrm{mg} / \mathrm{dL}$.

As médias gerais das concentrações de uréia e Nuréia plasmáticas foram de 46,33 e 21,59 mg/dL, respectivamente, e não diferiram entre os diferentes teores de NNP, o que provavelmente seria pelo fato de as dietas experimentais serem isoprotéicas, estando de acordo com MIRANDA et al. (1998), ao trabalharem com novilhas alimentadas com rações isoprotéicas, constituídas de $13 \%$ de $\mathrm{PB}$, cuja composição química apresentou $50 \%$ de $\mathrm{N}$ na forma de proteína verdadeira e $50 \%$ de NNP (uréia e cama de frango).

A concentração plasmática de $\mathrm{N}$-uréia obtida por VALADARES et al. (1997a), em vacas lactantes alimentadas com rações isoprotéicas (24\% de PB), foi em média $18,96 \mathrm{mg} \mathrm{N} / \mathrm{dL}$, enquanto ROSELER et al. (1993) obtiveram $14,8 \mathrm{mg} / \mathrm{dL}$ para a concentração plasmática de $\mathrm{N}$-uréia em vacas lactantes, para as quais foi fornecida dieta balanceada em termos de PDR e PNDR. Dietas de mesmo teor de PB, mas com excesso de PDR ou PNDR, resultaram em aumento da concentração plasmática de $\mathrm{N}$-uréia, cujos valores corresponderam a 16,5 e $17,8 \mathrm{mg} / \mathrm{dL}$. Este resultado está de acordo com MOSCARDINI et al. (1998), demonstrando, assim, que excesso de proteína verda-

Tabela 3 - Clearance da creatinina (CLCR), concentrações plasmáticas de creatinina (CRP), uréia (UP) e N-uréia (NUP), concentrações de uréia (UL) e N-uréia (NUL) no leite e a relação N-uréia:N total no leite (NUL/NTL), coeficiente de variação $(\mathrm{CV})$ e nível de probabilidade $(P)$ dos efeitos linear $(L)$ e quadrático $(Q)$

Table 3 - Creatinine clearance (CLCR), plasma concentrations of creatinine (CRP), urea (UP) and N-urea (NUP), urea (UM) and N-urea (NUM) concentrations in the milk and N-urea:total N ratio in the milk (NUM/NTM), coefficient of variation (CV) and level of probability $(P)$ of linear $(L)$ and quadratic $(Q)$ effects

\begin{tabular}{|c|c|c|c|c|c|c|c|}
\hline \multirow[t]{2}{*}{$\begin{array}{l}\text { Variáveis } \\
\text { Variables }\end{array}$} & \multicolumn{4}{|c|}{$\begin{array}{c}\text { Teores de NNP }(\%) \\
\text { NPN contents }\end{array}$} & \multirow[t]{2}{*}{$\mathrm{CV}(\%)$} & \multicolumn{2}{|c|}{$\mathrm{P}$} \\
\hline & 2,08 & 4,01 & 5,76 & 8,07 & & $\mathrm{~L}$ & Q \\
\hline $\mathrm{CLCR}(\mathrm{ml} / \mathrm{min} / \mathrm{kgPV})$ & 2,04 & 2,10 & 2,42 & 1,68 & 23,62 & n.s. & n.s. \\
\hline $\mathrm{CRP}(\mathrm{mg} / \mathrm{dL})$ & 1,15 & 1,13 & 1,10 & 1,33 & 13,83 & n.s. & n.s. \\
\hline $\mathrm{UP}(\mathrm{mg} / \mathrm{dL})$ & 45,52 & 41,75 & 55,34 & 42,70 & 17,54 & n.s. & n.s. \\
\hline $\operatorname{NUP}(\mathrm{mg} / \mathrm{dL})$ & 21,21 & 19,46 & 25,79 & 19,90 & 17,54 & n.s. & n.s. \\
\hline $\mathrm{UL}(\mathrm{mg} / \mathrm{dL})$ & 41,14 & 44,18 & 46,21 & 43,94 & 19,02 & n.s. & n.s. \\
\hline $\operatorname{NUL}(\mathrm{mg} / \mathrm{dL})$ & 19,17 & 20,59 & 21,53 & 20,48 & 19,02 & n.s. & n.s. \\
\hline NUL (g/dia) & 3,43 & 4,33 & 3,90 & 3,66 & 21,46 & n.s. & n.s. \\
\hline NUL/NTL $(\%)$ & 3,70 & 3,60 & 4,45 & 4,78 & 16,44 & 0,0088 & n.s. \\
\hline
\end{tabular}

Rev. bras. zootec., 30(6):1948-1957, 2001 
deira ou NNP e deficiência de energia da dieta resultam nas mais elevadas concentrações de uréia no plasma.

As concentrações médias de uréia e $\mathrm{N}$-uréia no leite (NUL) não foram afetadas $(\mathrm{P}>0,05)$ pelos teores de NNP, apresentando valores médios de 43,87 e $20,44 \mathrm{mg} / \mathrm{dL}$, respectivamente. SUSMEL et al. (1995b) relataram que a suplementação de uréia na dieta de vacas leiteiras resultou nas mais elevadas concentrações e excreções de N-uréia no leite. Resultado semelhante foi obtido por HINDERS (1996), que encontrou os maiores valores de NUL, 18,6 e $23,3 \mathrm{mg} / \mathrm{dL}$, em vacas recebendo os mais altos níveis de PDR e CNE, suplementados com 1,0 e 1,2\% de uréia na ração. Segundo o mesmo autor, uma variação individual de NUL em vacas poderá ser devida ao tipo de ração, a fatores genéticos, ao estado clínico do animal e aos dias após o parto.

A quantidade de NUL, em g/dia, variou de 3,43 a 4,33, com valor médio de $3,83 \mathrm{~g} / \mathrm{dia}$, o qual foi mais alto que o máximo relatado por BRODERICK e CLAYTON (1997). Resultados variando de 1,3 a 4,6 g/dia também foram demonstrados por ROSELER et al. (1993).

Houve aumento linear $(\mathrm{P}<0,05)$ na relação $\mathrm{N}$-uréia: $\mathrm{N}$ total no leite com a elevação dos teores de NNP das rações.

\section{Conclusões}

As excreções urinárias de uréia, alantoína, ácido úrico, as purinas absorvidas e a produção de $\mathrm{N}$ microbiano não foram influenciadas pelos níveis de NNP da dieta.

As concentrações de uréia e N-uréia no plasma e no leite não foram afetadas pela adição de quantidades crescentes de NNP à ração.

A excreção de creatinina apresentou valor médio de $23,60 \mathrm{mg} / \mathrm{kg}$ PV.

As excreções urinárias estimadas de uréia, alantoína e ácidoúriconão diferiram daquelas obtidas pela coleta total.

O volume urinário pode ser estimado com uma amostra de urina spot.

Estimativas a partir de amostra spot foram eficientes para as excreções de uréia e de DP e a produção de N microbiano.

\section{Referências Bibliográficas}

BRODERICK, G.A., MERCHEN, N.R. 1992. Markers for quantifying microbial protein synthesis in the rumen. J. Dairy Sci., 75:2618-2632.

BRODERICK, G.A. 1995. Use of milk urea as indicator of nitrogen utilization in lactating dairy cow. U.S. Dairy Forage Center 1995; Research Summaries. U. S. Departament of Agriculture, Agricultural Research Service. 122p.
BRODERICK, G.A., CLAYTON, M.K. 1997. A statistical evaluation of animal and nutritional factors influencing concentrations of milk urea nitrogen. J Dairy Sci., 80(11):2964-2971.

CECAVA, M.J., MERCHEN, N.R., GAY, L.C. et al. 1990. Composition of ruminal bacteria harvested from steers as influenced by dietary energy level, feeding frequency, and isolation techniques. J. Dairy Sci., 73(9):2480-2488.

CHEN, X.B., GOMES, M.J. 1992. Estimation of microbial protein supply to sheep and cattle based on urinary excretion of purine derivatives - an overview of technical details.(Occasional publication) INTERNATIONAL FEED RESEARCH UNIT. Bucksburnd, Aberdeen: Rowett Research Institute. 21p.

CHEN, X.B., MEJIA, A.T., KYLE, D.J. et al. 1995. Evaluation of the use of purine derivative: creatinine ratio in spot urine and plasma samples as an index of microbial protein supply in ruminants: studies in sheep. J. Agric. Sci., 125:137-143.

CHEN, X.B., SAMARAWEERA, L., KYLE, D.J. 1996. Urinary excretion of purine derivatives and tissue xanthine oxidase (EC 1.2.3.2.) active in buffalloes (Bubalis bubalis) with special reference to differences between buffalloes and Bos taurus cattle. Br. J. Nutr., 75:397-407.

CLARK, J.H., KLUSMEYER, T.H., CAMERON, M.R. 1992. Microbial protein synthesis and flows of nitrogen fractions to the duodenum of dairy cows. J. Dairy Sci., 75(8):2304-2323.

CUNNINGHAN, J.G. 1993. Tratado de fisiologia veterinária. Rio de Janeiro: Guanabara Koogan. 454p.

DEPETERS, E.J., FERGUSSON, J.D. 1992. Nonprotein nitrogen and protein distribution in the milk of cows. J. Dairy Sci., 75(11):3192-3209.

FUJIHARA, T., ORSKOV, E.R., REEDS, P.J. et al. 1987. The effect of protein infusion on urinary excretion of purine derivatives in ruminants nourished by intragastric nutrition. J. Agric. Sci., 109:7-12.

FUNABA, M., KENSUKE, K., TSUNENORI, I. et al. 1997. Duodenal flow of microbial nitrogen estimated from urinary excretion of purine derivatives in calves after early weaning. J. Anim. Sci., 75(7):1965-1973.

GIESECK, D., EHRENTREICH, L., STANGASSINGER, M. 1994. Mammary and renal excretion of purine metabolites in relation to energy intake and milk yield in dairy cows. J. Dairy Sci., 77(8):2376-2381.

GONDA, H.L., LINDBERG, J.E. 1997. Effect of diet on milk allantoin and its relationship with urinary allantoin in dairy cows. J. Dairy Sci., 80(2):364-373.

GUSTAFFSON, A.H., PALMQUIST, D.L.1993. Diurnal variation of rumen ammonia, serum urea and milk urea in dairy cows at high and low yields. J. Dairy Sci., 76(2):475-484.

HARMEYER, J., MARTENS, H. 1980. Aspects of urea metabolism in ruminants with reference to the goat. J. Dairy Sci., 63(10):1707-1728.

HINDERS, R. 1996. MUN indicates adequacy of protein, carbohydrates in milking cow rations. Feedstuffs., p.11

HOOVER, W.H., STOKES, S.R. 1991. Balancing carbohydrates and proteins for optimum rumen microbial yield. J. Dairy Sci., 74(10):3630-3644.

JOHNSON, L.M., HARRISON, J.H., RILEY, R.E. 1998. Estimation of the flow of microbial nitrogen to the duodenum using urinary uric acid or allantoin. J. Dairy Sci., 81(9):2408-2420.

JONKER, J.S., KOHN, R.A., ERDMAN, R.A. 1998. Using milk urea nitrogen to predict nitrogen excretion and utilization efficiency in lactating dairy cows. J. Dairy Sci., 81(10):2681-2692.

LENINGHER, A.L., NELSON, D.L., COX, M.M. 1995. Princípios de bioquímica. 2.ed. São Paulo: Savier. 839p. 
LOBLEY, G.E., CONNELL, A., LOMAX, M.A. et al. 1995. Hepatic detoxification of ammonia in the ovine liver: possible consequences for amino acid catabolism. Br. J. Nutr., 73(5):667-685.

MAYES, R.W., DOVE, H., CHEN, X.B. et al. 1995. Advances in the use of faecal and urinary markers for measuring diet composition, herbage intake and nutrient utilization in herbivores. In: JOURNET, M., GRENET, E., FARCE, MH. (Eds.). Recent developments in the nutrition of herbivores. Paris, 1995. p.381-406.

MERCHEN, N.R., BOURQUIN, L.D. 1994. Processes of digestion and factors influencing digestion of forage-based diets by ruminants. In: FAHEY JR., G.C. (Ed). Forage quality, evaluation, and utilization. Madison. p.564-602.

MIRANDA, L.F., QUEIROZ, A.C., VALADARES FILHO, S.C. et al. 1998. Efeito da proteína dietética na concentração da uréia plasmática de novilhas. In: REUNIÃO ANUAL DA SOCIEDADE BRASILEIRA DE ZOOTECNIA, 1,1998, Botucatu. Anais... Botucatu: SBZ, 1998. p.71-73.

MORRISON, M., MACKIE, R.I. 1996. Nitrogen metabolism by ruminal microorganisms: current understanding and future perspectives. Aust. J. Agric. Res., 47(2):227-246.

MOSCARDINI, S., WRIGHT, T.C., LUIMES, P.H. et al. 1998. Effects of rumen-undegradable protein and feed intake on purine derivative and urea nitrogen: comparison with predictions from the Cornell Net Carbohydrate and Protein System. J. Dairy Sci., 81(9):2421-2429.

NOCEK, J.E., RUSSEL, J.B. 1988. Protein and energy as an integrated system. Relationship of ruminal protein and carbohydrate availability to microbial synthesis and milk production. J. Dairy Sci., 71(8):2070-2107.

NOLAN, J.V. 1993. Nitrogen kinetics. In: FORBES, J.M., FRANCE, J. (Eds.) Quantitative aspects of ruminant digestion and metabolism. Wallingford: C.A.B. International. p.123-143.

PEREZ, J.F., BALCELLS, J., GUADA, J.A. et al. 1996. Determination of rumen microbial-nitrogen production in sheep: a comparison of urinary purine excretion with methods using ${ }^{15} \mathrm{~N}$ and purine bases as markers of microbial-nitrogen entering the duodenum. Br. J. Nut., 75:699-709.

PUCHALA, R., KULASEK, G.W. 1992. Estimation of microbial protein flow from the rumen of sheep using microbial nucleic acid and excretion of purine derivatives. Can. J. Anim. Sci., 72:821-830.

RENNÓ, L.N. Produção de proteína microbiana utilizando derivados de purinas na urina, concentração plasmática de uréia e excreções de uréia e creatinina em novilhos. Viçosa, MG: UFV, 1999.91p. Dissertação (Mestrado em Zootecnia) - Universidade Federal de Viçosa, 1999.

ROSELER, D.K., FERGUNSON, J.D., SNIFFEN, C.J. et al. 1993. Dietary protein degradability effects on plasma and milk urea nitrogen and milk nonprotein nitrogen in Holstein cows. J. Dairy Sci., 76(2):525-534.

RUSSEL, J.B., O'CONNOR, J.D., FOX, D.J. et al. 1992. A net carbohidrate and protein system for evaluating catle diets: I. Ruminal fermentation. J. Anim. Sci., 70(11):3551-3561.

SIDDONS, R.C., NOLAN, J.V., BEEVER, D.E et al. 1985. Nitrogen digestion and metabolism in sheep consuming diets containing contrasting forms and levels of N. Br. J. Nutr., 54(1):175-187.

SILVA, R.M.N., VALADARES, R.F.D., VALADARES FILHO, S.C. et al. 2001. Uréia para vacas em lactação: 1Consumo, digestibilidade e produção de leite. Rev. bras. zootec., 30(5):1639-1649.

SNIFFEN, C.J., ROBINSON, P.H. 1987. Microbial growth and flow as influenced by dietary manipulations. J. Dairy Sci., 70:425-441.
STANGASSINGER, M., CHEN, X.B., LINDBERG, J.E. et al. 1995. Metabolism of purines in relation to microbial production. In: INTERNATIONAL SYMPOSIUM ON RUMINANT PHYSIOLOGY, 8, Stuttgart, 1995. Proceedings... Ferdinand Enke Verlag Stuttgart, 1995. p.387-406.

SUSMEL, P., STEFANON, B., PLAZZOTT, E. et al. 1994. The effect of energy and protein intake on the excretion of purine derivatives. J. Agric. Sci., 123:257-266.

SUSMEL, P., SPANGHERO, M., STEFANON, B. 1995a. Nitrogen balance and partitioning of some nitrogen catabolites in milk and urine of lactating cows. Livest. Prod. Sci., 44:207-219.

SUSMEL, P., STEFANON, B., SPANGHERO, M. 1995b. Daily variation of purine derivatives concentration in urine of cows fed once or twice daily. Zoot. Nutr. Anim. 21:145-153.

THOMSON, D.U., PRESTON, R.L., BARTLE, S.J. 1995. Influence of protein source and level on the performance, plasma urea nitrogen and carcass characteristic of finishing beef steers. J. Anim. Sci., 73(1):257.

THORNTON, R.F., WILSON, B.W. 1972. Factors affecting the urinary excretion of urea nitrogen in cattle. III. High plasma urea nitrogen concentrations. Aut. J. Agric. Res., 23(4):727-734.

TIMMERMANS JR., S.J., JOHNSON, L.M., HARRISON, J.H. et al. 2000. Estimation of the flow of microbial nitrogen to the duodenum using milk uric acid or allantoin. J. Dairy Sci., 83(6):1286-1299.

TOPPS, J.H., ELLIOTT, R.C. 1967. Partition of nitrogen in the urine of African sheep given a variety of low-protein diets. Anim. Prod., 9:219-227.

UNIVERSIDADE FEDERAL DE VIÇOSA - UFV. 1998. SAEG - Sistema de análises estatísticas e genética. Versão 8.0. Viçosa, MG. (Manual do usuário). 150p.

VAGNONI, D.B., BRODERICK, G.A., CLAYTON, M.K. et al. 1997. Excretion of purine derivatives by Holstein cows abomasally infused with incremental amounts of purines. $J$. Dairy Sci., 80(8):1695-1702.

VAGNONI, D.B., BRODERICK, G.A. 1997. Effects of supplementation of energy or ruminally undegraded protein to lactating cows fed alfalfa hay or silage. J. Dairy Sci., 80(8):1703-1712.

VALADARES, R.F.D., BRODERICK, G.A., VALADARES FILHO, S.C. et al. 1999. Effect of replacing alfalfa silage with high moisture corn on ruminal protein synthesis estimated from excretion of total purine derivatives. J. Dairy Sci., 82(12):2686-2696.

VALADARES, R.F.D., GONÇALVES, L.C., RODRIGUEZ, N.M. et al. 1997a. Níveis de proteína em dietas de bovinos. 4. Concentrações de amônia ruminal e uréia plasmática e excreções de uréia e creatinina. R. Bras. Zootec., 26(6):1270-1278.

VALADARES, R.F.D., GONÇALVES, L.C., RODRIGUEZ, N.M. et al. 1997b. Metodologia de coletas de urina em vacas utilizando sondas de Folley. R. Bras. Zootec., 26(6):1279-1282.

VERBIC, J., CHEN, X.B., MaCLEOD, N.A. et al. 1990. Excretion of purine derivatives by ruminants. Effect of microbial nucleic acid infusion on purine derivative excretion by steers. J. Agric. Sci., 114(3):243-248.

VISEK, W.J. 1979. Ammonia metabolism, urea cycle capacity and their biochemical assessment. Nutr. Rev., 37:273-282.

WITTWER, F., REYES, J.M., OPITZ, H. et al. 1993. Determinación de urea em muestras de leche de rebaños bovinos para el diagnóstico de desbalance nutricional. Arch. Med. Vet., 25(2):165-172.

Recebido em: 24/10/00 Aceito em: 25/06/01 